\title{
Algunas cuestiones pendientes sobre las es- tampas de la Varia Commensuracion de Juan de Arfe y un posible dibujo inédito de Pedro Ru- biales
}

$M^{a}$ del Carmen Heredia Moreno

Universidad de Alcalá

RESUMEN. En este artículo se analiza la autoría de los dibujos preparatorios y de las estampas de la Varia Commensuracion de Juan de Arfe. También se concretan las influencias artísticas de Gaspar Becerra y, por último, se atribuye la estampa del f37v al pintor Pedro Rubiales, a partir de un dibujo con anagrama hasta ahora desconocido.

Palabras clave: Juan de Arfe, Gaspar Becerra, Pedro Rubiales, dibujos, grabados.

ABSTRACT. Juan de Arfe's authorschip of preparatory drawings and engravings for the Varia Commensuracion are analyzed in this paper. Also, the contacts between Arfe and Gaspar Becerra are specified. Finally, the drawing of the $\mathrm{f} 37 \mathrm{v}$ is attributed to the painter Pedro Rubiales from an umpublished anagram.

Key words: Juan de Arfe, Gaspar Becerra, Pedro Rubiales, drawings, engravings.

En recientes trabajos sobre Juan de Arfe Villafañe he abordado el tema de sus fuentes artísticas para tratar de cubrir la laguna existente sobre la procedencia de sus trazas arquitectónicas y de sus diseños figurativos. Los resultados de estas investigaciones han puesto de manifiesto cómo su pensamiento teórico, inspirado en tratadistas y en modelos europeos, se plasma realmente en su obra práctica y en las estampas de la Varia Commensuracion para la Esculptura y Architectura ${ }^{1}$. Sin embargo, sobre las

\footnotetext{
${ }^{1}$ M. C. Heredia MORENO, «Juan de Arfe Villafañe y Sebastiano Serlio», Archivo Español de Arte, nº 304, 2003, pp. 371-388 y "Sobre las fuentes artísticas de Juan de Arfe", El arte foráneo en España. Presencia e influencia, Madrid, 2005, pp. 307-318.
}

ilustraciones de esta última obra quedan todavía algunas incógnitas, ya que aun no se ha resuelto de manera definitiva el problema de la autoría. La cuestión es importante porque se trata de un conjunto de alrededor de trescientos grabados, es decir, del tratado de arte con mayor número de ilustraciones de nuestro siglo XVI.

Según el actual estado de la cuestión, la opinión más generalizada defiende que todas las estampas de la Varia son obra personal de Juan de Arfe, pero la falta de documentos y de firmas ha generado ciertas discrepancias y contradicciones entre los estudiosos, sobre todo por lo que respecta a los dibujos de anatomía y de arquitectura. Bonet Correa considera que el dibujo, e 
incluso la estampa, del pretendido autorretrato de la contraportada de la Varia, al estar representado de perfil, sería necesariamente de algún maestro de su entorno y propone como autor a su hermano Antonio el Mozo (Fig. 1)². También le niega Bonet la autoría de algunos de los dibujos de la desaparecida colección del Instituto Jovellanos de Gijón, que desde los tiempos de Sánchez Cantón se venían considerando de mano de Juan y preparatorios para su tratado ${ }^{3}$. La atribución al platero la mantuvieron Angulo y Pérez Sánchez en 1975, apoyándose tanto en la bibliografía tradicional como en la inscripción de su nombre y apellidos, escritos con pluma y con rasgos propios de la época, que figura en todos ellos ${ }^{4}$. Pero, según Bonet, sólo el de la cabeza en escorzo recuerda a la figura 4 del Libro II, título III, capítulo 21 , folio $27 \mathrm{v}$ y cabrían ciertas dudas respectos a los tres dibujos de cuerpo entero que, aunque diferentes a los del Libro II, se aproximan a las figurillas de algunos relieves de sus obras en plata.

De acuerdo con esta última opinión, añadimos por nuestra parte que el desnudo de la izquierda repite, aunque invertido y con distinto modelo de cabeza, la composición general de la figura masculina del folio $13 \mathrm{v}$ y $37 \mathrm{v}$ del Libro II, por lo que cabe la posibilidad de que estos dibujos sean ejerci-

\footnotetext{
2 A. BONET CORREA, Figuras, modelos e imágenes en los tratadistas españoles, Madrid, 1993, pp. 42-44. Se trataría de una de las últimas obras de Antonio, que debió morir poco antes de marzo de 1586, a juzgar por la fecha y por el prólogo de Juan a la edición del libro Vida y Fábulas Exemplares de Esopo, traducidas al castellano por su hermano Antonio.

${ }^{3}$ A. BONET CORREA, Figuras..., pp. 88-89 y F. J. SÁNCHEZ CANTÓN, Los Arfe, escultores de la plata y el oro, Madrid, 1920, p. 49 y lám. XVIII, reproduce el de los tres desnudos masculinos de cuerpo entero y lo califica de admirable y de mano personal de Arfe. Los dio a conocer MORENO VILLA, Dibujos del Instituto de Gijón, Madrid, 1990, núms. 487-489.

${ }^{4}$ D. Angulo ÍÑiguez y A. E. PÉRez SÁnCHez, A corpus of spanish drawings, Londres, 1975, Vol. I, pp. 1920
}

cios o estudios de anatomía hechos por el propio Juan de Arfe para utilizar luego en su obra, quizás siguiendo indicaciones de Gaspar Becerra o de Esteban Jordán ${ }^{5}$. En este contexto hay que incluir también el dibujo de un busto masculino de frente y de espaldas procedente de la colección Cardedera, que hoy se guarda en la Biblioteca Nacional de Madrid ${ }^{6}$. Angulo y Pérez Sánchez lo consideraron una copia temprana del folio 27 del libro II de la Varia Commensuracion, edición de $1675^{7}$. Pero, habida cuenta de que las estampas de esta edición del siglo XVII están calcadas de la primera de 1585-1587, también podría argumentarse que el dibujo fuera el original o una copia de la edición princeps. De hecho, su calidad y su técnica son similares a las del grabado.

En el año 1979 Antonio Gallego puso en duda también, aunque sin quitarle mérito al artífice, que Arfe "labrara las maderas", basándose en un conocido párrafo de la Descripción de la traça y ornato de la custodia de plata de la Santa Iglesia de Sevilla, Sevilla, 1587 que dice textualmente: "y quisiera yo hallarme desocupado y con tallador liberal y suficiente para poder mostrarlas, particularmente en diseño, como las lleva la obra..." ${ }^{\prime 8}$. Pero el platero se refiere en estas líneas a las historias, figuras y jeroglíficos

\footnotetext{
${ }^{5}$ Algunos datos sobre la relación Arfe-Becerra en M. C. HEREDIA MORENO, «Sobre las fuentes artísticas...», p. 308.

6 BARCíA: Catálogo de la colección de dibujos originales de la Biblioteca Nacional, Madrid, 1906, núm. 1 .

${ }^{7}$ D. Angulo Íñiguez y A. E. PÉRez SÁnChez, A corpus..., fig. 10 .

${ }^{8}$ Un resumen de esta obra publicaron primero A. PONZ, Viaje por España, Madrid, 1786, segunda edición, T. IX, pp. 56-62 (Hay edición facsímil, Madrid, 1972) y más tarde J. A. CEÁN BERMúDEZ, "por haberse hecho raro este escrito", en: Diccionario histórico de los más ilustres profesores de las Bellas Artes en España, Madrid, 1880, T. I. pp. 60-64 (Hay edición de Madrid, 2001, con prólogo de M. MORÁN TURINA). La primera reedición completa la dio a conocer el mismo CEÁN en la revista Archivo Hispalense, Sevilla, 1887, pp. 19-30.
} 
de la custodia que, efectivamente, quedaron sin grabar, por lo que la Descripción se editó sin estampas ${ }^{9}$. Por nuestra parte, consideramos que la causa de tal omisión pudo ser que Juan andaba muy ocupado en estos momentos terminando la pieza de plata para la catedral hispalense y repitiendo los dos últimos libros del manuscrito de la Varia Commensuración que, a causa del incendio que se cita en el prólogo, se había publicado incompleta en la edición de $1585^{10}$. Pero para Gallego "parece más prudente colocar a Juan de Arfe entre los inspiradores y animadores del libro ilustrado que entre los talladores" ${ }^{\prime 1}$.

Sin embargo el Conde de la Viñaza le adjudicó la portada de la segunda parte de la Historia de Sevilla, de Alonso Morgado, impresa en Sevilla en el mismo año y en la misma imprenta de Andrea Pescioni y Juan de León donde se había editado la Varia ${ }^{12}$. En ella se representa a las santas Justa y Rufina, de cuerpo entero, "grabadas en plomo y muy bien dibujadas, obras sin duda de Juan de Arfe, porque siguen su estilo y carácter (el de la Varia), así en el modo de diseño como en el de grabar, porque la santa Justa tiene al pie una A, monograma de su apellido..." (Fig. 2) ${ }^{13}$. Esta

9 A. GAllego, La historia del grabado en España, Madrid, 1979, pp. 111 y ss. Este historiador se pregunta si no sería Antonio de Arfe, platero y grabador, el "tallador liberal y suficiente" que su hermano Juan echa de menos en el folleto descriptivo de la custodia y apunta la posibilidad de que Antonio fuese el autor de las estampas del Quilatador.

${ }^{10}$ J. DE ARFE Y VILlafañE, De Varia Commensuración para la Esculptura y Architectura, Sevilla, 1585 y 1587 (Hemos consultado los originales de la Biblioteca Nacional de Madrid, R/3415 y V/1202)

11 A. GALLEGO, La historia del grabado..., p. 113.

${ }^{12}$ A. MorgADO, Segunda parte de la historia de Sevilla,en la qual se contienen sus antigvedades, grandezas, y cosas memorables en ella acontecida, compvesta y ordenada por..., En Sevilla. En la Imprenta de Andrea Pescionni y Iuan de Leon. 1587.

${ }^{13}$ CONDE DE LA VIÑAZA, Adiciones al Diccionario histórico de los más ilustres profesores de las Bellas Artes en apreciación nos parece incorrecta, al menos por lo que se refiere a lo que se reproduce bajo la imagen de la santa, difícil de identificar a causa de su tamaño diminuto, pero que creemos se trata de varias figuras humanas. No obstante, es cierto que el dibujo de contorno y la estilización de las santas sevillanas guardan cierta semejanza con los tipos femeninos que encuadran el escudo de la portada del Quilatador de la plata, oro y piedras, editado por vez primera en Valladolid en el año 1572 (Fig. 3).

Recientemente, Alfonso Jiménez ha llamado la atención sobre los dibujos anatómicos de los folios 125, 125v y 146 del Libro de Arquitectura de Hernán Ruiz el Joven que reproducen un brazo y dos piernas con los huesos de la mano y el pie y los "morcillos", a la manera del Libro II de la Varia de Arfe, es decir, con la misma intención artística mejor que médica ${ }^{14}$. Por último, García López considera de Arfe el retrato de Rodrigo Zamorano incluido en su Cronología y repertorio de la razón de todos los tiempos, editado también en Sevilla en 1587 en la misma imprenta de Andrea Pescioni y Juan de León, por semejanza con el del platero que aparece en la contraportada de la Varia Commensuracion ${ }^{15}$. Ambos retratos coinciden, efectivamente, en su marco ovalado y en la composición de busto largo y de perfil, aunque el tamaño del primero es bastante mayor. Sin embargo, conviene recordar aquí la atribución que hizo Bonet del retrato de Juan a su hermano Antonio.

Por lo que respecta a las estampas de animales del libro II de la Varia Commensuración, Bonet Correa opina que están toma-

España compuesta y ordenada por Don Agustín Ceán Bermúdez, Madrid, 1889, T. I. p. 23.

14 A. JIMÉNEZ, «Miscelánea», en Libro de Arquitectura. Hernán Ruiz II, Sevilla, 1998, Vol. II, pp. 270-271.

15 GARCíA LÓPEZ, «De "platero" a "escultor y arquitecto" de plata y oro". Juan de Arfe y la teoría artística», en Estudios de platería. San Eloy 2002, Murcia, 2002, p. 154. 
das de las ilustraciones de la Historiae Animalium de Konrad Gessner, publicado en 1550, excepto la del rinoceronte que está copiada de Alberto Durero ${ }^{16}$. No obstante, investigaciones en curso permiten añadir otras posibles fuentes que, hasta ahora, no se habían tenido en cuenta ${ }^{17}$.

En cuanto a las láminas de arquitectura, Sanz Serrano apunta la posibilidad de que la estampa del Libro IV, título II, capítulo $\mathrm{V}$, fol. $38 \mathrm{v}$, que representa el alzado de la custodia de la catedral de Sevilla, de inferior calidad que las restantes, sea obra de otra mano más torpe ${ }^{18}$.

A tenor de todo lo expuesto, se pone de manifiesto la diversidad de criterios y lo problemático del actual estado de nuestros conocimientos sobre las estampas de la Varia $^{19}$. Abundando en estas cuestiones, llamamos ahora la atención sobre la figura masculina, de frente y de cuerpo entero, del folio 37v del Libro II, sin duda una de las mejores de todo el conjunto, y añadimos, como detalle muy importante que hasta el momento había pasado desapercibido, que la estampa contiene varias letras sobre una de las piedras de la parte inferior izquierda (Fig. 4). Se trata de un confuso anagrama cuya interpretación nos revelaría al autor de, al menos, esta estampa o del dibujo preparatorio, ya que parece el anagrama de un nombre propio. Pero resulta imposible identificarlo con las iniciales de Juan de Arfe (Fig. 5) y ni siquiera podemos comprobar si esta estampa firmada es la misma que se utilizó en la edición de 1585, porque

\footnotetext{
16 A. BONET CORREA: Figuras, modelos e imágenes..., p. 63.

${ }^{17}$ M. C. Heredia MORENO: «Un álbum de dibujos del taller de Berruguete propiedad de los V Duques del Infantado» (En elaboración).

${ }^{18} \mathrm{M}^{\mathrm{a}}$ J. SANZ SERRANO: Juan de Arfe Villafañe y la custodia de Sevilla, Sevilla, 1978, pp. 59-60.

${ }^{19}$ En estos momentos estamos trabajando sobre otros posibles dibujos preparatorios para las estampas de la Varia.
}

al único ejemplar que conocemos de esta primera edición incompleta le faltan varios folios entre el que se incluye el que nos interesa $^{20}$. No obstante, en el terreno de la hipótesis proponemos dos posibles lecturas, puesto que, a simple vista, el anagrama parece "Rㅡ", pero un análisis más detenido permite también interpretarlo como " $\mathrm{P} \% / \mathrm{u}$ ", con la "u" (o quizás "v") muy abierta y unida a la " $\mathrm{P}$ " formando el palo diagonal de una " $R$ ".

Si aceptamos la primera lectura $-\mathrm{R}^{\mathrm{o}-\text {, }}$ tendríamos que pensar en un autor de nombre Rodrigo que, en el entorno de Juan de Arfe nos llevaría a Rodrigo Zamorano. Recordemos que Zamorano, medio paisano de Arfe y residente en Sevilla desde el año 1574, era un científico y humanista de actividad polifacética. Además de astrólogo, matemático y catedrático de cosmografía en la Casa de Contratación, se relacionó con el canónigo Francisco Pacheco y con los círculos de la Academia hispalense y fue el primero que tradujo al castellano el tratado De re aedificatoria de Alberti y Los seis primeros libros de Geometría de Euclides ${ }^{21}$. En las estampas que incorporó en su traducción

\footnotetext{
20 Nos referimos al de la Biblioteca Nacional, signatura R/3415, que es el que cita Ceán y recoge E. LlagunO y AmIROLA: Noticia de los Arquitectos y Arquitectura en España desde su Restauración, por el Excmo. Sr. D..., ilustradas y acrecentadas con notas, adiciones y documentos por D. Agustín Ceán Bermúdez, III, pp. 98-99. Este ejemplar debe ser el que utilizó BONET en la edición facsímil de la Varia Commensuración para la Esculptura y Architectura, Libros I y II, Madrid, 1974. La portada de este ejemplar con firma autógrafa de Juan de Arfe es el se reproduce también en El Libro de Arte en España, Granada, 1975, nº 18

${ }^{21}$ Sobre la traducción de Alberti puede consultarse A. J. MORALES, «Arte y ciencia en la Sevilla del siglo XVI. Los manuscritos del cosmógrafo Rodrigo Zamorano», Actas del X Congreso del CEHA. Los Clasicismos en el Arte Español, Madrid, 1994, pp. 453-457 y «El cosmógrafo Rodrigo Zamorano, primer traductor de Alberti al español», Annali di Architecttura, 7, 1995, pp. 141-146. Sobre la traducción de Alberti hemos manejado De re aedificatoria, edición de Madrid, 1991, con prólogo de J. RIBERA.
} 
de la obra de Euclides editada en Sevilla en 1576 demuestra sus amplios conocimientos sobre geometría y dibujo ${ }^{22}$. Además, si son suyos los grabados de figuras humanas intercalados en su libro Repertorio y cronología de los tiempos, publicado en esta misma ciudad y en la misma imprenta diez años más tarde, se pone de manifiesto también que poseía cierta capacidad para el dibujo figurativo ${ }^{23}$.

No obstante, la calidad de estas estampas del Repertorio, como la del folio $316 \mathrm{v}$, nos lleva a descartarlo como posible autor de las figuras de la Varia (Fig. 6). En todo caso cabría suponer que Zamorano ayudase a Arfe en los dibujos preparatorios del Libro I de Geometría, materia ésta para la que el matemático y cosmógrafo sí estaba perfectamente cualificado. Pero la figura masculina de la Varia sobrepasa, creemos, las posibles facultades de Rodrigo como dibujante y como grabador. Es sin duda la mejor estampa de todo el Libro II y una excelente muestra de un clasicismo italianizante, con rasgos romanistas similares a los de algunas imágenes de Gaspar Becerra.

Parecido carácter, aunque con la anatomía menos detallada, se advierte en las figuras de los folios $13 \mathrm{v}$ y 39 , esta última con un desnudo femenino, también de frente y de cuerpo entero, que Arfe utiliza para explicarnos su idea sobre las proporciones de una mujer adulta (Fig. 7). Su tipo físico de cuerpo blando y dilatado, así como la fisonomía del rostro y la disposición del cabello se aproximan a los de la Venus de la lámina VI del conocido libro de Valverde de Hamusco, Historia de la composición del

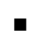

${ }^{22}$ Un comentario sobre su actividad en Sevilla con la bibliografía correspondiente en M. C. HEREDIA MORENO, «Juan de Arfe Villafañe y Sebastiano Serlio», p. 377 y ss.

${ }^{23}$ R. ZAMORANO, Repertorio..., Otra estampa con figuras humanas es la que corresponde al jeroglífico del año. cuerpo humano, Roma, $1556^{24}$, obra atribuida a Gaspar Becerra por su semejanza con la imagen de la Opulencia que el baecetano había pintado en la Sala de'Cento Giorno del Palazzo de la Cancellería de Roma (Fig. $8)^{25}$. En estas pinturas, hechas bajo la dirección de Giorgio Vasari, colaboró también el extremeño Pedro Rubiales, amigo personal de Becerra, según Ceán Bermúdez, y con un gusto romanista muy próximo al del pintor y escultor andaluz ${ }^{26}$. Se da la circunstancia de que Rubiales estuvo implicado en las ilustraciones del libro de Valverde y da también la casualidad que la segunda lectura del anagrama del folio $37 \mathrm{v}$ de la Varia $\mathrm{P} / \mathrm{u}$ nos permitiría identificarlo con su nombre $\left(\mathrm{P}^{\mathrm{o}}=\right.$ Pedro $)$ y apellido $(\mathrm{Ru}$ o $\mathrm{Rv}=$ Rubiales o Ruviales).

Es decir, por lo que concierne a la paternidad de las estampas de la Varia nos enfrentamos a una situación parecida a la de las láminas del Tratado de anatomía de Valverde de Hamusco, publicado en Roma en 1556 coincidiendo con la estancia de Becerra y Rubiales en la Ciudad Eterna, que tantas dudas ha suscitado entre los historiadores $^{27}$. El primero que señaló a Gaspar Becerra como autor de los dibujos del "Valverde español" fue Vicente Carducho en sus Diálogos de la Pintura, calificándolo de excelente dibujante ${ }^{28}$. Pacheco ensalzó las

-

${ }^{24}$ J. VALVERDE DE HAMUSCO: Historia de la composición del cuerpo Humano, Roma, 1556, Tab. VI del Libro III, fig. XXX. Hemos consultado el ejemplar de la Biblioteca Nacional de Madrid, R.16488

${ }^{25}$ C. FRACCHIA, «La herencia italiana de Gaspar Becerra en el retablo mayor de la catedral de Astorga», Anuario del Departamento de Historia y Teoría del Arte (U.A.M.), Vols. IX-X, 1997-1998, 133-151, Fig. 3.

${ }^{26}$ A. CEÁN BERMúdEZ, Diccionario histórico de los más ilustres profesores de las Bellas Artes en España, Madrid, 1800, T. IV, p. 275, (Hay edición reciente, en Madrid, 2001, con prólogo de M. MORÁN TURINA).

27 J. VAlVERDE DE HAMUSCO: Historia de la composición....

${ }^{28}$ V. CARDUCHO, Diálogos de la Pintura, Madrid, 1633. La edición de Madrid, 1979, con prólogo y notas de F. Calvo Serraller, p. 25-26. Además, en la p. 126 
figuras "debuxadas valientemente de mano de Becerra, ilustre ingenio español" ${ }^{29} \mathrm{y}$ Antonio Palomino lo calificó de "grandísimo anatomista" ${ }^{\prime 30}$. En nuestros días ha sido Martín González el que ha mantenido esta atribución, recogiendo también el parecer de Post de que "los (grabados) del libro de Valverde discurren por un cauce estético, que aproxima las figuras a los modelos habituales del arte clásico ${ }^{31}$.

Por el contrario, Llaguno y Amirola señaló que el propio Valverde había elogiado de forma desmedida a un Pedro Rubiales, extremeño, en el texto de su tratado de anatomía, situándolo a la altura de Miguel Ángel $^{32}$. La cita textual de Valverde dice así: “...nos lo han hecho ver en nuestro tiempo Miguel Ángel florentín y Pedro de Rubiales estremeño, los cuales por averse dedicado a la Anatomía, juntamente con la pintura, an venido a ser los más excellentes y famosos pintores que grandes tiempos a se an visto ..."33. A esta misma cita se refirieron posteriormente José Parada y Santín, profesor de anatomía pictórica de la Escuela Superior de Bellas Artes de San Fernando en 1894, Rogelio Buendía y Juan Riera, interpretándola los dos últimos historiadores como

dice: "Enseñóme un amigo unos dibujos de becerra Español, que para mí fue fiesta doble. No podía apartarme de mirar aquellos perfiles tan airosos, tan fundados en arte y ciencia y tan cumplidos en todo..."

${ }^{29}$ F. PACHECO, El Arte de la Pintura, Libro II, p.384. Hemos consultado la edición de 1990, con introducción y notas de B. Bassegoda i Hugas.

${ }^{30}$ A. PAlomino de CASTRO Y Velasco, Museo Pictórico y Escala Óptica, Madrid, 1947, p. 781, con prólogo de J. A. Ceán Bermúdez

31 J. J. MARTín GONZÁleZ: «Precisiones sobre Gaspar Becerra», Archivo Español de Arte, no 168 (1969) 333. En efecto, la figura XXX del Libro II procede de la Venus de Médicis, la de la tabla X evoca el Diadúmenos y la de la tabla $\mathrm{V}$ parece un santo anacoreta.

32 A. CEÁN BERMúDEZ: Diccionario histórico..., T. III, pp. 275-276.

33 J. VALVERDE DE HAMUSCO, Historia de la composición..., Lib. II / Tabla III. signo de una estrecha amistad ${ }^{34}$. En efecto, si tales alabanzas fueran ciertas, habría que suponer una buena relación entre ambos personajes y habría que contemplar también la posibilidad de que Rubiales hubiese participado en la elaboración de los dibujos preparatorios para Valverde. Recordemos, por otra parte, que Rubiales fue amigo de Becerra y su colaborador en la pintura de la mencionada Sala del palacio romano, lo que presupone también una relación continuada e intensa y un gusto artístico similar. De hecho, Vasari llegó a afirmar que "los españoles Bizerra y Roviale trabajaron mucho tiempo conmigo y aprendieron mucho en esta obra" ${ }^{35}$. Fernando Checa atribuye al extremeño todo el conjunto de ilustraciones $^{36}$ y Carmen Fracchia sólo asegura la mano de Becerra en el frontispicio del libro (Fig. 9) y en la imagen femenina inspirada en la pintura de la Abundancia del palacio de la Cancilleria de Roma, antes citada ${ }^{37}$.

Paralelamente, se ha venido considerando que las láminas del tratado de Valverde son de Nicolaus Beatrizet, opinión que ha generado también la correspondien-

\section{-}

34 J. PARADA Y SANTÍN: Anatomía pictórica: ensayo de antropología artística, Madrid, 1894, capítulo «Apuntes para la historia de la Anatomía Artística», p. 43 y ss. R. BUENDÍA: «Pintura», en Historia del ArteHispánico III. Renacimiento, Madrid, 1980, p. 262. J. Riera: Valverde y la anatomía del Renacimiento, Madrid, 1981, pp. 42-45, hace un ajustado estado de la cuestión sobre las diferentes atribuciones a Becerra y Rubiales hasta 1981, insiste en el enorme peso de la cita de Valverde a favor de Rubiales y concluye apuntando que la colaboración entre los dos pintores explicaría las argumentaciones a favor de ambos.

${ }^{35}$ G. VASARI, Vidas de artistas ilustres, traducido de la edición italiana de 1568 por A. Blánquez y otros, Barcelona, 1957, Vol. V, p. 368.

${ }^{36}$ F. CHECA CREMADES, «La imagen impresa en el Renacimiento y el Manierismo», en El grabado en Espa$\tilde{n} a$ (Siglos XV-XVIII), Madrid, 1987, p. 134.

${ }^{37}$ C. FRACCHIA, «La herencia italiana de Gaspar Becerra en el retablo mayor de la catedral de Astorga», Anuario del Departamento de Historia y Teoría del Arte (U.A.M.), Vols. IX-X (1997-1998) 133-151. 
te bibliografía ${ }^{38}$. En este caso, suponemos que la atribución se fundamenta en la estampa del mencionado libro que reproduce la figura erguida y de frente de un hombre despellejado (Fig. 10) ${ }^{39}$. La lámina contiene un anagrama "NB" en una de las piedras de la parte inferior izquierda de la base, por cierto en un sitio análogo al de la estampa de la Varia, que cabe interpretar sin ningún problema como las iniciales de su nombre y apellido. Nicolaus Beatrizet era natural de Lunéville, se encontraba en Roma desde 1540 y desde 1548 a 1553 efectuó numerosos grabados sobre la Antigüedad y sobre la pintura contemporánea romana de los seguidores de Rafael $^{40}$. Su estancia en la Ciudad Eterna en las fechas de preparación y edición del libro es un dato importante para corroborar su participación en las ilustraciones. Pero, como este artífice era grabador de profesión, su labor, en nuestra opinión, debió limitarse a abrir las planchas a partir de los dibujos hechos por Gaspar Becerra o por Pedro Rubiales.

En cambio, las planchas de la Varia Commensuracion se imprimieron en Sevilla entre 1585 y 1587 y ninguno de los dos artistas españoles pasaron por la ciudad andaluza en estas fechas. Becerra había muer-

-

${ }^{38}$ Véase, por ejemplo, la bibliografía recogida por R. LÓPEZ TORRIJOS, «Los años de El Escorial: imágenes históricas y simbólicas. A 29. Beatricetto Niccolò», en El Escorial en la Biblioteca Nacional. IV Centenario del Monasterio de El Escorial, Madrid, 1985-1986, pp. 92-93. También el estudio de D. SuÁREZ Quevedo: «ArteCiencia (Anatomía) en el Renacimiento Español. La obra de Juan Valverde de Hamusco y su Clasicismo», en Actas del X Congreso del CEHA. Los Clasicismos en el Arte Español, Madrid, 1994, pp. 475-483. V.

${ }^{39}$ J. VALVERDE De HAMUSCO, Historia de la..., lam.

${ }^{40}$ BENEZIT, Dictionnaire critique et documentaire des peinares, sculpteurs, dessinateurs et graveurs de tous les temps, París, 1976, Vol. I, p. 545. Uno de los anagramas de Beatrizet que reproduce coincide con el de la lámina que nos ocupa. También se recoge la actividad de Nicolaus Beatricet en Saur Allgemenines KünstlerLexicon, Manchen-Leipzig, 1994, T. 8, pp. 52-53 to diecisiete años antes y el extremeño se quedó en Roma donde falleció también hacia $1570^{41}$

A tenor de todo lo expuesto y por lo que respecta al tratado de Juan de Arfe, es preciso recordar ahora los complicados avatares de la "Edición princeps" de la Varia Commensuracion para tratar de clarificar algunas cuestiones. Es evidente que la estructura general de la obra estaba trazada completa desde el principio, es decir, desde antes de la edición de 1585, ya que en su prólogo se indica expresamente que el conjunto va dividido en cuatro libros. Sin embargo en esta primera edición sólo se incluyeron los dos primeros, mientras que la publicación de los libros III y IV se demoró hasta el año 1587 por circunstancias que resultan un tanto confusas, pese a la aclaración contenida en la licencia correspondien$t^{42}$. En efecto, como Palomero Páramo puso de manifiesto, en el encabezamiento del texto de 1585 figura la licencia y el privilegio para editar y vender la obra durante seis años, más la solicitud y la concesión de una prórroga durante otros veinte en atención a que el artífice había tenido que repetir el texto completo y todas las planchas de los dibujos, porque tanto el manuscrito

\footnotetext{
${ }^{41}$ E. LlagunO y Amirola: Noticia de los arquitectos y arquitectura en España desde su restauración, (Edic. facsímil, Madrid, 1977, T. II, pp. 261-263.

${ }^{42}$ Como señaló J. PALOMERO PÁRAMO, "«uevos datos sobre el proceso editorial de la "Varia Commensuracion" de Juan de Arfe: La fe de erratas y la tirada inicial de los dos primeros libros», en Homenaje al profesor Hernández Perera, Madrid, 1993, pp 887-993. D. J. A. CEÁn Bermúdez, Noticia de los Arquitectos y Arquitectura en España desde su Restauración, por el Excmo. Sr. D. Eugenio Llaguno y Amirola, ilustradas y acrecentadas con notas, adiciones y documentos por..., Madrid, 188, T. III, pp. 88-89, fue el primero que aludió a la fragmentación editorial de la Varia... aunque consideró que la causa fue un incendio fortuito que destruyó "los diseños de los animales...para el tercer libro. Los grabó en $1587 . .$. y aunque tuviese concluido el cuarto, no quiso publicarlo, como era regular, hasta que finalizase el tercero; por lo que no se vendió la obra completa hasta $1587 . . . "$.
} 
original como todos los grabados en madera se destruyeron en un incendio fortuito. La Cámara Real accedió a lo solicitado a condición de que Arfe remitiese al Consejo el nuevo texto impreso con la correspondiente fe de erratas para cotejarlas con el manuscrito, ateniéndose en este punto a lo dispuesto en la Real Pragmática de Felipe II sobre el control estatal de las ediciones, dada en Valladolid en 7 de septiembre de $1558^{43}$.

Sin embargo, dicha fe de erratas es muy reducida. Sólo consta de seis erratas, que únicamente se refieren a los dos primeros libros, es decir a los que efectivamente se publicaron en el 1585, indicando de forma expresa el escribano público de Sevilla Juan de Velasco que "Juan de Arfe...hizo un libro: Primera y Segunda parte de la Baria

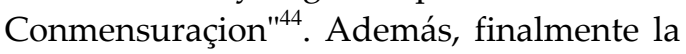
fe de erratas no se incorporó en esta primera edición incompleta, ni en la de 1587, pese a haberse mandado "ymprimir hasta en cantidad de mill erratas para mill libros", es decir, un pliego de erratas para cada uno de los mil ejemplares que se tiraron. Esta omisión va en contra de lo que solía hacerse en la época, como demuestra, por ejemplo, la primera edición del Qvilatador de la plata, oro y piedras..., editado en Valladolid en 1572 ó el libro de Rodrigo Zamorano: Repertorio y cronología de los tiempos, editado en la misma imprenta sevillana de Andrea Pescioni y Juan de León en 1587, ambos con su correspondiente fe de erratas incorporada en los primeros folios.

\footnotetext{
43 J. PALOMERO PÁRAMO, «Nuevos datos sobre el proceso editorial ...», pp 887-993. P. PASCUAL, «Felipe II y su política legislativa sobre el libro», Felipe II y su época. Actas del Simposium (II), San Lorenzo de El Escorial (Madrid), 1998, pp. 226 y ss.

${ }^{44}$ Hemos revisado el documento original, ya publicado por Palomero en su mencionado artículo, procedente del Archivo Histórico de Protocolos Notariales de Sevilla, Oficio XII, Libro de 1585, folio 482, que incluye un pliego con una fe de seis erratas, tres para cada uno de los dos primeros libros.
}

Es decir, la primera edición de la $V a$ ria se atiene en líneas generales a la normativa en vigor en cuanto a la solicitud y obtención de las pertinentes licencias, pero por alguna ignorada razón no cumple con el requisito habitual de incluir la fe de erra$\operatorname{tas}^{45} \mathrm{y}$ tampoco se corrigen dichas erratas en el texto, como hemos tenido ocasión de comprobar $^{46}$. Por otra parte, el hecho de que el tratado se publicase incompleto, pese a la indicación expresa de que se componía de cuatro libros, parece indicar que los plazos editoriales para repetir la obra fueron muy cortos, por lo que la repetición del texto y de las estampas de estos dos primeros libros se tuvo que producir de forma precipitada. Por lo tanto, quizás fuera esta falta de tiempo la que impulsó a Arfe a utilizar el dibujo del pintor extremeño para una de las láminas de su tratado.

$\mathrm{Si}$ aceptamos que el dibujo original que sirvió para la estampa del Libro II, folio $37 \mathrm{v}$ de la Varia es de Pedro Rubiales, tendríamos también que considerar que el vehículo más lógico de transmisión habría sido Gaspar Becerra, ya que los dos pintores se habían relacionado en Roma y colaborado en algunos proyectos romanos. Además, por testimonios documentales sabemos que Becerra había traído consigo de Italia un arca con modelos que, a su muerte, se encontraba en poder del pintor vallisoletano Jerónimo Vázquez, según testimonio de su viuda Paula Velázquez ${ }^{47}$.

\footnotetext{
${ }^{45}$ Aparte de la bibliografía que cita Palomero en su artículo, puede consultarse P. PASCUAL: «Felipe II y Plantino», Actas del III Congreso Nacional de Historia del Papel en España, 1999, pp 297-320.

${ }^{46}$ Puede comprobarse esta circunstancia cotejando las erratas recogidas en el citado documento notarial con los folios y párrafos correspondientes del ejemplar de la Varia editado en 1585 (Biblioteca Nacional, R. 3415) o con la edición facsímil de 1974 con estudio de Bonet Correa.

${ }^{47}$ Figuran en el testamento de Gaspar Becerra que publicó E. LlAGUNO Y AMIROLA, Noticias de los arquitectos y arquitectura de España desde su restauración, edic.
} 
También trajo dibujos, como el papel del Juicio Final de Miguel Ángel que, según García Chico, tenía en su taller su discípulo Esteban Jordán, el cual, a su vez, lo dejó en herencia a su yerno Pedro de Oña ${ }^{48}$.

Por lo tanto, cabe considerar el dibujo que nos ocupa también lo trajo de Italia Gaspar Becerra y en Valladolid se lo regaló a Esteban Jordán o a Juan de Arfe, tanto como prueba de amistad, cuanto como ejemplo práctico del gusto romano de la época y del suyo personal en anatomía y en proporciones o como posible modelo para que el escultor o el platero lo utilizasen en sus propias obras, habida cuenta que se mostraban muy interesados por el arte italiano contemporáneo. Ambos artistas habían tenido ocasión de conocer personalmente a Gaspar durante el tiempo en que coincidieron en Valladolid a partir de su regreso de Italia y de su llegada a la localidad en 1557. Además, Jordán fue discípulo del baecetano y amigo personal de Arfe desde su infancia ${ }^{49}$. Por otra parte, Palomino y Ceán insinuaron una posible amistad entre
Arfe y Becerra a través de los comentarios que pusieron en boca del primero con motivo de la temprana muerte del segundo, acaecida en Madrid en $1568^{50}$. De cualquier manera, al utilizar el dibujo traído por el andaluz, aun cuando su autor hubiera sido una tercera persona, Juan se declaraba ferviente admirador del Romanismo miguelangelesco ejemplificado en la obra de Pedro Rubiales. Además, al realizar el grabado, el platero pudo incorporar el anagrama, a la manera de Durero, para dejar constancia de la autoría del extremeño.

La falta de tiempo para cubrir los plazos editoriales quizás obligase también a Juan a solicitar la ayuda de su amigo Rodrigo Zamorano para algunos dibujos de geometría y, por la misma razón, la edición de los libros III y IV se demoró durante dos años. Tales prisas abren también la posibilidad de que Arfe tuviera que valerse de la ayuda de un amanuense para la repetición del texto del manuscrito ${ }^{51}$. facsímil Madrid, 1977, T. II, pp. 261-263. El codicilo de su mujer lo publicó M. ARIAS MARTíNEZ, “Gaspar Becerra, escultor o tracista. La documentación testamentaria de su viuda, Paula Velázquez", Archivo Español de Arte, 끈 283, 1998, pp. 277 y 286.

${ }^{48}$ Lo recoge J. J. MARTín GONZÁLEZ: Esteban Jordán, Valladolid, 1952, p. 50. También M. SERRANO MARQUÉS: «Gaspar Becerra y la introducción del Romanismo en España», Boletín del Museo e Instituto Camón Aznar, nº 78-79, 1999, p. 211, recoge dos dibujos de Mercurio y Diana, de mano de Becerra, que poseía su paisano el platero Juan de Ledesma, establecido en Madrid en el año 1590.

${ }^{49}$ Sobre las relaciones y amistades de Arfe en Valladolid puede consultarse M. C. HEREDIA MORENO, «Sobre las fuentes artísticas de Juan de Arfe y Villafañe», pp. 307-312.
${ }^{50}$ A. Palomino y Velasco, Museo pictórico y escala óptica, Edición de Madrid, 1947 con prólogo de Ceán Bermúdez. En el T. III «El Parnaso español pintoresco y laureado», p. 786, afirma que "tiénese por cierto que fue en Madrid..., a poco más de los cincuenta de su edad, como lo significa Juan de Arfe". El propio Ceán Bermúdez en su Diccionario..., T. I. p. 112 afirma que falleció en Madrid en 1570 "siendo aun joven, como se lamentaba Juan de Arfe su amigo".

${ }^{51}$ M.C. HEREDIA MORENO: «Un manuscrito muy poco conocido de la Varia Commensuracion de Juan de Arfe», en prensa. 


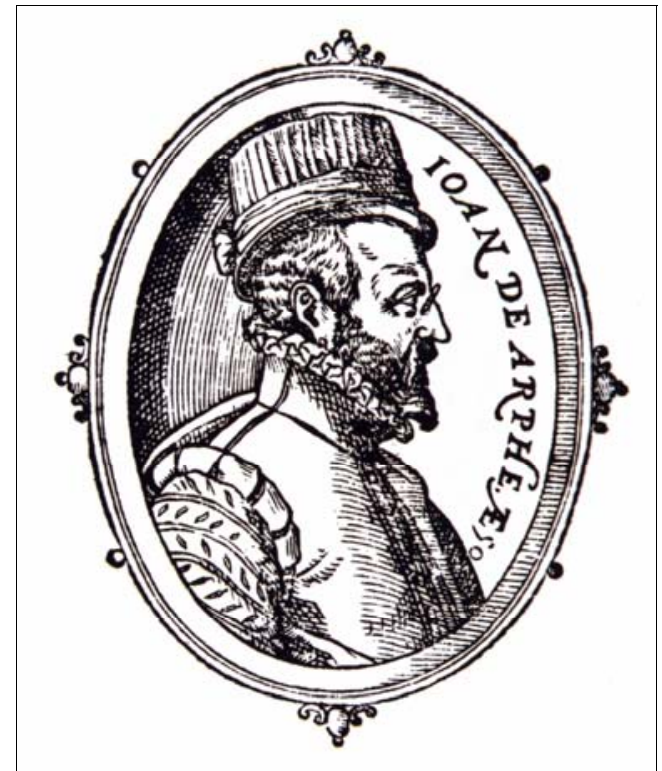

- Fig. 1. Retrato de Juan de Arfe.

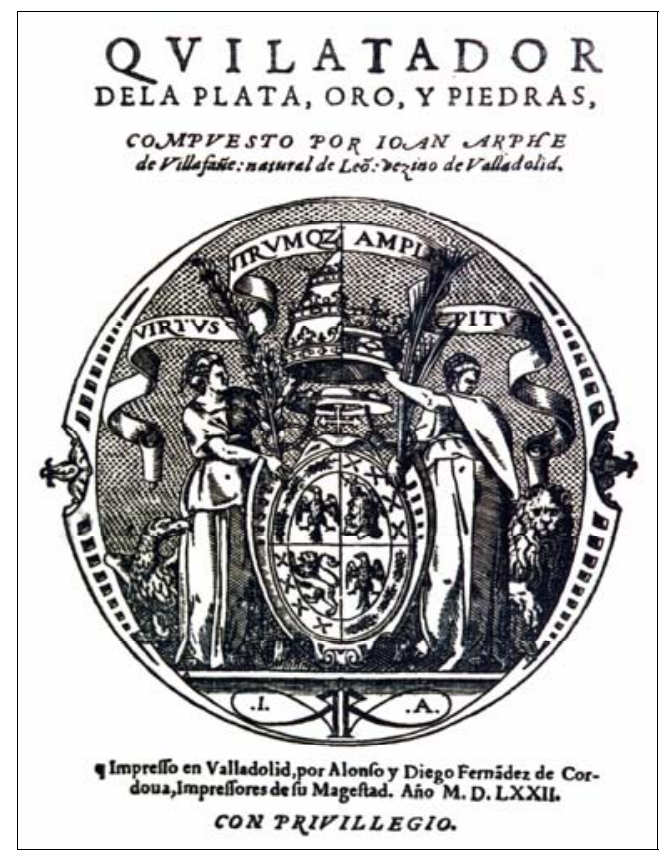

- Fig. 3. J. de Arfe: Quilatador...Portada.
Compuesta, y ordenada por el mismo Autor Alonso Morgado, indigno Sacerdote.

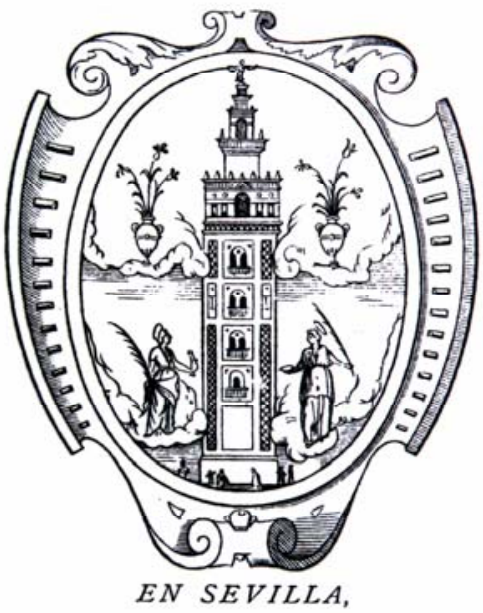

En la Imprenta de Andrea Pescioni, y Inan de Leon. ${ }^{1} 5^{8} 7$.

- Fig. 2. A. Morgado: Historia de Sevilla. Portada

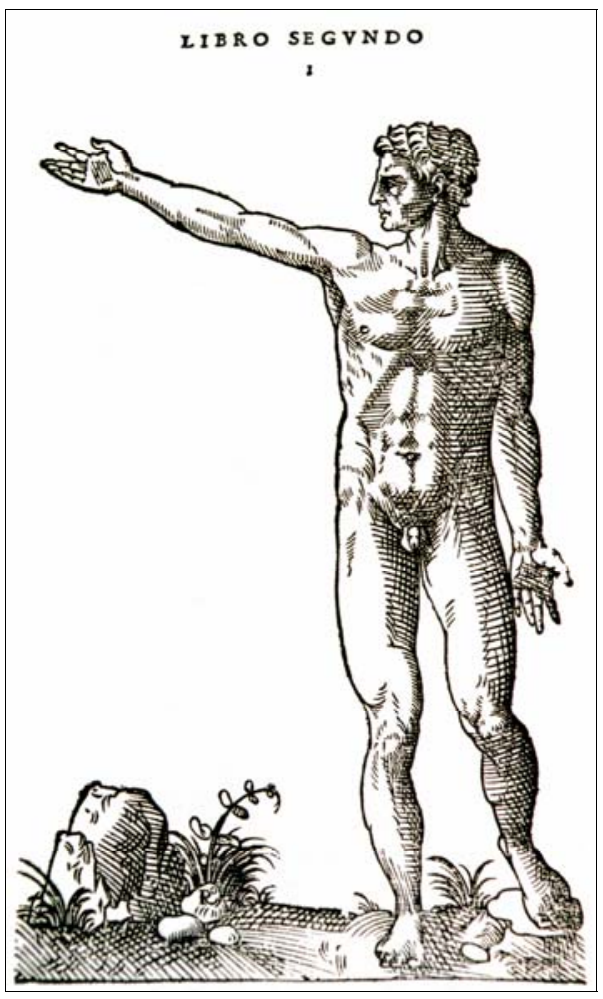

- Fig. 4. J. de Arfe: De Varia..., Libro II, fol. $37 \mathrm{v}$. 


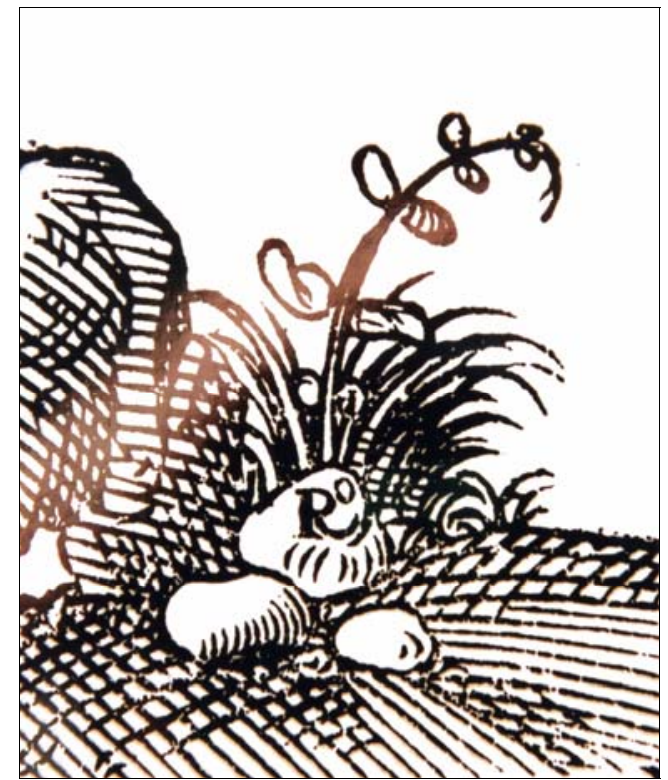

- Fig. 5. J. de Arfe: De Varia..., Libro II, fol. 37v (Detalle).

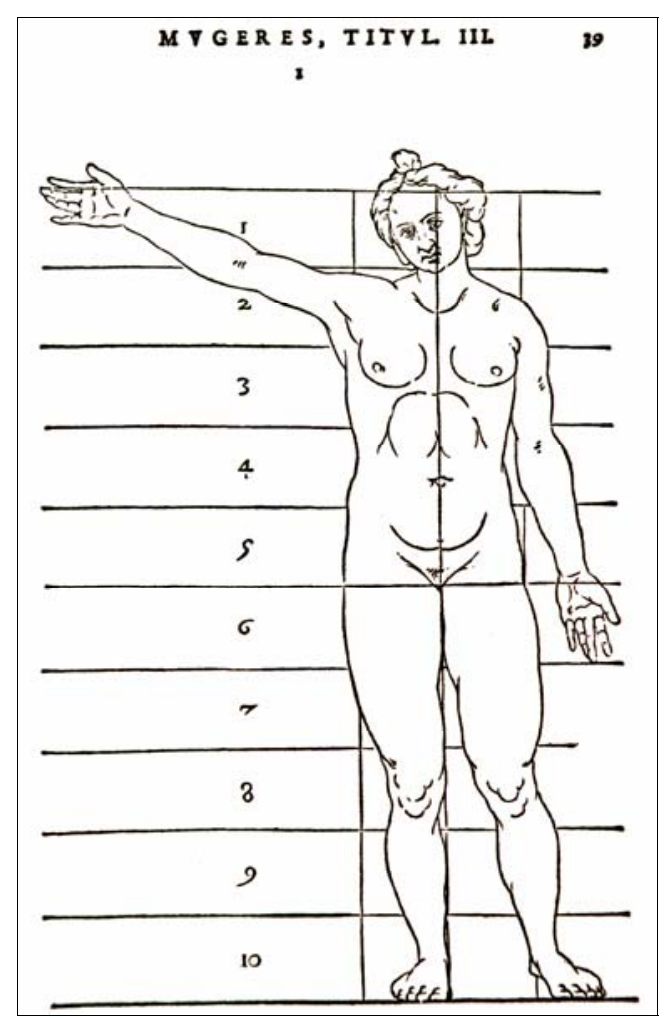

- Fig. 7. J. de Arfe: De Varia..., Libro II, fol. 39.

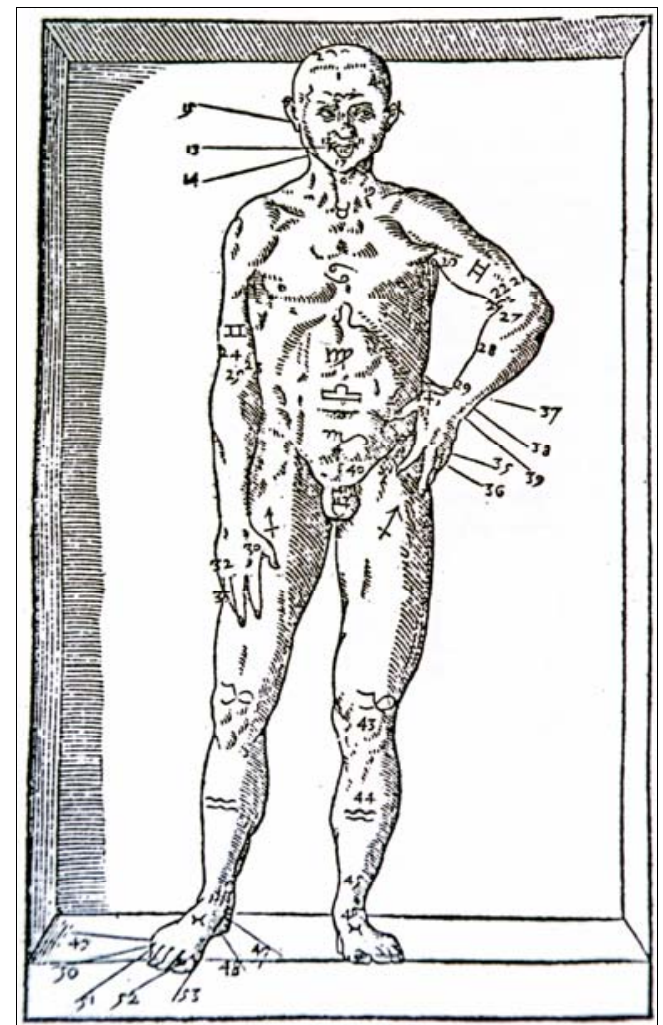

- Fig. 6. R. Zamorano: Repertorio..., fol. 316v.

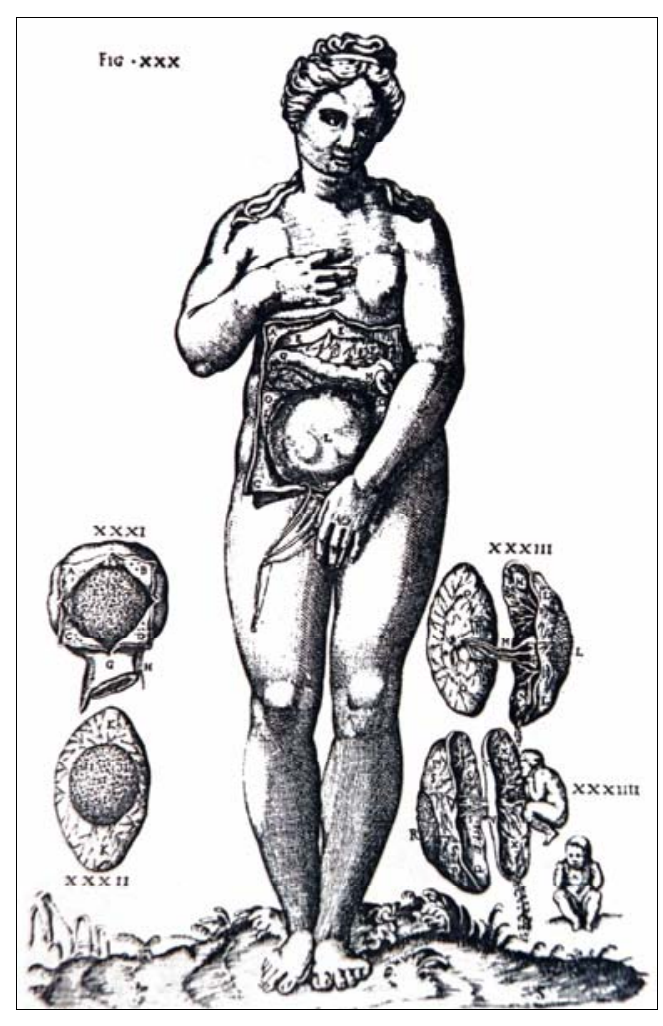

- Fig. 8. J. Valverde de Hamusco: Historia...Lámina 6. 


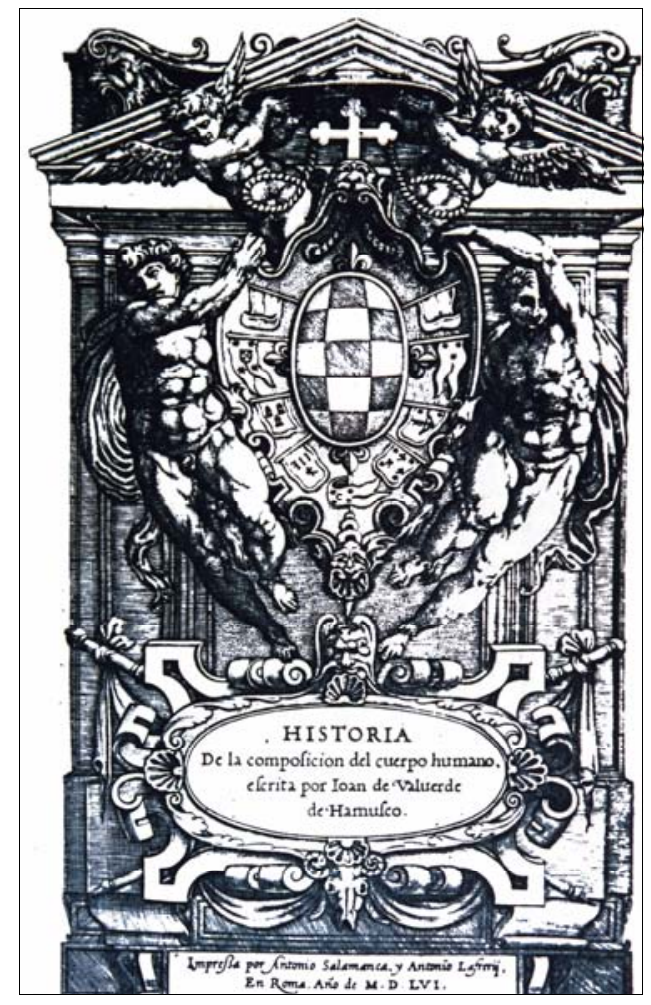

- Fig. 9. J. Valverde de Hamusco: Historia... Portada.

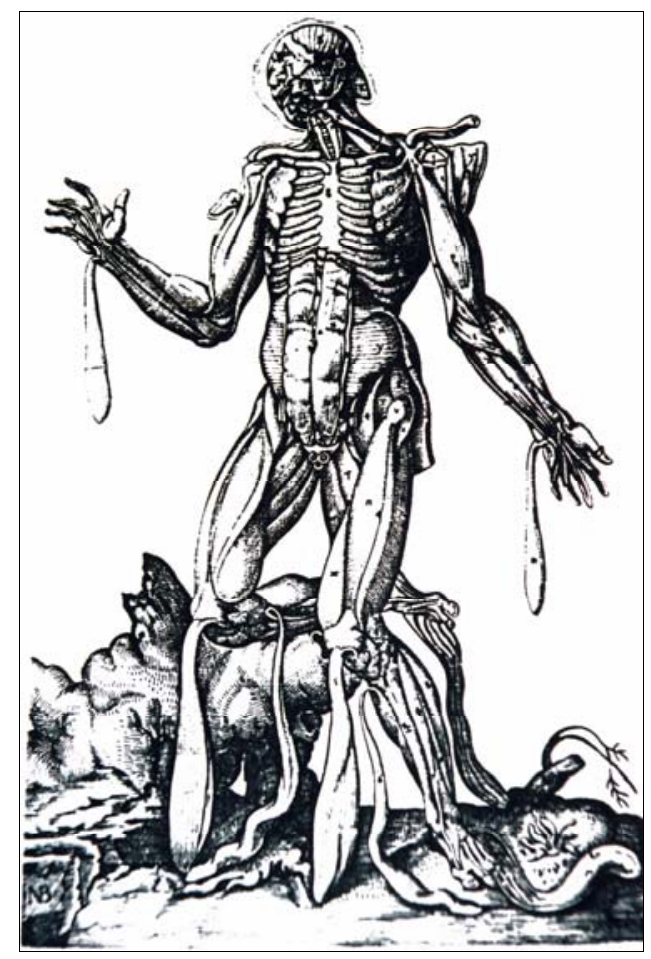

- Fig. 10. J. Valverde de Hamusco: Historia... Hombre despellejado. 